\title{
A DIDÁTICA MAGNA: UMA OBRA PRECURSORA DA PEDAGOGIA MODERNA?
}

\author{
Ronaldo Aurélio Gimenes Garcia \\ Universidade Federal da Fronteira Sul
}

\section{RESUMO}

A pedagogia contemporânea tem suas origens na modernidade, ou seja, um período da história marcado por intensas transformações econômicas, religiosas, sociais e de mentalidade. Foi em meio a este turbilhão de mudanças que surgiu Comênio e sua célebre obra Didática Magna. Perspicaz observador da nova realidade que se desenhava com o desfecho do mundo feudal e o nascimento da sociedade do capital, o autor protestante propunha outro modelo de educação que rompia com o ensino praticado no período medieval. A moderna pedagogia ia desde uma profunda reformulação dos métodos didáticos até a organização e funcionamento das instituições de ensino que deu origem ao atual modelo de escola. Na concepção de Comênio educar era também uma forma de salvar as almas. A educação permitiria ao indivíduo conhecer melhor Deus e Suas manifestações. Atento ao desenvolvimento científico de sua época, o mencionado pensador inovou ao imaginar uma metodologia de ensino em que o aluno teria contato direto com a natureza, perfazendo assim os mesmos passos que os pesquisadores percorriam para chegar a uma determinada resposta. Tratava-se de fato da pedagogia do aprender fazendo.

Palavras-chave: Comênio; pedagogia moderna; história da educação.

\section{THE GREAT DIDACTICS: A PRECURSORY WORKMANSHIP OF THE MODERN PEDAGOGY}

\begin{abstract}
The pedagogy contemporary has its origins in modernity, that is, a period of the history marked for intense economic, religious, social transformations and of mentality. It was in way to this eddy of changes that appeared Comênio and its celebrates Great Didactic workmanship. Perspicacious observer of the new reality that if drew with the outcome of the feudal world and the birth of the society of the capital, the protestant author considered another model of education that breached with the education practiced in the medieval period. The pedagogy modern went since a deep reformularization of the didactic methods until the organization and functioning of the education institutions that gave origin to the current model of school. In the conception of Comênio to educate age also a form to save the souls. The education would allow the individual to know God and Its manifestations better. Intent to the scientific development of its time, the thinking mentioned one innovated when imagining an education methodology where the pupil would have direct contact with the nature, thus prefaced the same steps that the researchers covered to arrive at one definitive reply. One was in fact about the pedagogy of learning making.

Keywords: Comenius; modern pedagogy; history of education.
\end{abstract}




\section{Introdução}

Um mundo conturbado e marcado por intensas transformações anuncia o início do que se convencionou chamar de modernidade. $\mathrm{O}$ comércio e as manufaturas estavam em franco processo de expansão, as cidades cresciam e desafiavam o velho modelo dos burgos medievais com suas ruas tortuosas e estreitas. O catolicismo que até então, era no Ocidente a única igreja cristã, viu sua hegemonia ameaçada com o surgimento e rápida difusão das idéias reformistas. Foi em e meio a este turbilhão de acontecimentos que viveu Comênio, tido como o grande pensador e difusor da pedagogia moderna.

O objetivo deste texto e discutir as propostas de Comênio para a educação, identificando nelas o modelo de organização e funcionamento que ainda perdura no atual modelo de ensino, ou ainda aqueles que, no caso do Brasil, não foram ainda alcançados plenamente. Embora inovadora e à frente de seu tempo, Didática Magna também apresenta uma missão, ou seja, salvar a alma de todos os indivíduos por meio da educação.

Antes de avançarmos na questão proposta pelo texto é preciso conhecer um pouco melhor o contexto histórico em que o autor da Didática Magna, João Amós Comênio, a concebeu. Para tanto precisamos entender o agitado período que marcou o final da Idade Média e o surgimento da modernidade. A Europa estava mergulhada em conflitos religiosos. A reforma protestante ganhava cada vez mais adeptos e estimulava o florescimento de novas seitas, como foi o caso da doutrina dos Irmãos Morávios, a qual Comênio e sua família participavam. O clima de perseguições, guerras e constante instabilidade política, foram as características marcantes da vida de Comênio.

Pensar um novo tipo de sociedade e educação, conduzidas pela solidariedade e pelo conhecimento como forma de aproximar-se de Deus, foi o objetivo maior desse pensador que deixou marcas definitivas no estudo e na prática pedagógica dos últimos cinco séculos da humanidade.

Comênio nasceu no final do século XVI na Morávia, região que pertencia ao Reino da Boêmia, hoje República Tcheca. Os moradores daquela região seguiam os preceitos religiosos de Jan Huss, reitor da Universidade de Praga. A seita local defendia um forte apego às Escrituras Sagradas e uma rigidez de costumes, com notório apelo religioso em favor da fraternidade do grupo. Segundo Gasparin (1997) desde o início os Irmãos se preocupavam em desenvolver a educação de todos, incluindo adultos, crianças, jovens e mulheres. Talvez esse fato tenha sido um dos motivos da preocupação de Comênio com o ensino, haja vista que é impraticável separar a obra pedagógica do autor e sua militância religiosa.

\section{Comênio e seu tempo}

A origem dos Irmãos Morávios remonta ao século XV. Eles estavam sob a liderança de John Huss. Havia uma proposta de reforma religiosa aliada à autonomia da região e do fortalecimento da língua e da cultura boêmia (Kulesza, 1992). Devido à perseguição religiosa Huss foi condenado e queimado vivo pelo Tribunal da Inquisição em 1415. Com isso os conflitos se intensificaram mais ainda e motivou os adeptos do hussismo a continuarem a sua luta de resistência. Como característica própria da organização dos hussistas, além da preocupação com a educação, estava também o cuidado de preservar o idioma local. No início todo o conteúdo era transmitido na língua vernácula, porém como forma de concorrência com as escolas católicas, passou também a ensinar latim. 
Comênio iniciou seus estudos nas escolas dos Irmãos. Por volta dos 16 anos ficou órfão e, após concluir os seus estudos secundários, foi para universidade na Alemanha em Herborn. No ambiente universitário tomou contato com importantes obras e pensadores como Andrea Alciati, Giovanni Domênico Campanella e Juan Luís Vives. As utopias dessa época iriam marcar definitivamente o pensamento do autor de Didática Magna, levando-o a pensar em uma solução pacífica para os conflitos religiosos em um período histórico dominado pela intolerância. Conhece também o pensamento pedagógico de Johann Heinrich Alsted e o método didático de Wolfgang Ratke. Após o retorno, Comênio assume a direção da escola dos Irmãos e começa a produzir seus primeiros estudos.

Disputas internas entre a dinastia dos Habsburgo, sobre o comando do rei espanhol Felipe II, avançaram sobre a região da Boêmia a ponto de destituir o rei Frederico V (protestante) e instalar Fernando II (católico), incentivando assim um forte movimento de perseguição aos desertores da Igreja de Roma. Teve início a Guerra dos Trinta Anos que ocorreu entre 1618 e 1648 e envolveu diversos conflitos políticos e religiosos entre diferentes nações europeias. Este fato afastou Comênio de sua terra natal e o condenou ao exílio para o resto de sua existência. Foi durante essa crítica fase de sua vida que o autor escreveu a maior parte de suas obras. Entre elas a Didática Magna. Kuleszca (1992) afirma que durante essa época o ilustre pensador morávio aproximou-se de estudos como a cabala, a alquimia e o misticismo. Chegou mesmo a fazer parte da Ordem Rosacruz. Uma organização de caráter místico-filosófica que surgiu na Europa no século XVII que reuniu diversos grupos de protestantes. A influência dos místicos e fanáticos na obra de Comênio foi notória. Ele mesmo publicou diversos ensaios condenando o método cartesiano de Descartes. Tido como um atentado ao pensamento cristão.

Conviveu Comênio com um contexto histórico marcado por muitas transformações ocorrendo ao mesmo tempo. Anterior ao Iluminismo e contemporâneo ao Renascimento, à Reforma Religiosa e à Contra-Reforma era possível identificar um momento de transição entre o final do feudalismo e a expansão da economia comercial dos séculos XVI e XVII, principalmente em função das grandes navegações. Por um lado a sociedade estamental, o absolutismo e o mercantilismo, representavam um empecilho ao livre desenvolvimento das forças produtivas do capitalismo. Não foi por acaso que somente no século XVIII com a derrubada do poder absolutista (Revolução Francesa) e do mercantilismo (Revolução Industrial), o capital expandiu-se enormemente e vingou o modelo burguês de classes sociais (Hobsbawm, 1995). O pensamento não estava imune a todas estas transformações. Havia uma nítida contradição entre as tentativas de conciliar o espírito religioso com os novos elementos da modernidade nascente, como o antropocentrismo, o individualismo, o racionalismo e a busca e o acúmulo de riquezas materiais.

\section{Uma pedagogia para a modernidade}

Nos anos quatrocentos uma rica e próspera burguesia já dava evidentes sinais de seu crescimento, o comércio marítimo, principal atividade do período, permitia a expansão das cidades e uma maior concentração urbana. Estas mudanças em curso refletiam em vários setores da vida social e geravam novas demandas que antes eram ignoradas. Foi justamente no seio da vida privada que muitas alterações operaram.

Segundo Cambi (1999) a partir do século XV um novo modelo de família e educação foi implantado. Durante a idade média o primogênito era o único dos filhos que recebia uma preparação para desempenhar os papéis da vida adulta. Os demais eram criados sem muitos cuidados e expectativas. No entanto com a modernidade surgia uma preocupação cada vez mais evidente de cuidar dos pequenos não só assegurando condições 
de sobrevivência, mas garantindo também uma educação mais cuidadosa e afetiva. $\mathrm{O}$ próprio modelo de família muda significativamente, ao invés das grandes famílias patriarcais, ganhava espaço os núcleos parentais formados essencialmente por pai, mãe e filhos.

\begin{abstract}
A família, objeto de uma retomada como núcleo de afetos e animada pelo 'sentimento da infância', que faz cada vez mais da criança o centro-motor da vida familiar, elabora um sistema de cuidados e de controles da mesma criança, que tendem a confirmá-la a um ideal, mas também a valorizá-la como um mito, um mito de espontaneidade e inocência, embora ás vezes obscurecido por crueldade, agressividade etc. (CAMBI, 1999, p. 204).
\end{abstract}

A escola também sofreu uma mudança significativa que de certa forma rompeu com o ensino veiculado pelas escolas católicas, muito baseado em métodos mnemônicos e individualizado que predominou ao longo do período anterior ao século XV. Naquele período as instituições escolares não possuíam de um modelo de organização sistematizado. Em uma mesma sala de aulas havia alunos de várias idades; ausência de um currículo estabelecido; constante indisciplina e outros problemas.

Na Idade Média, família e escola tinham - comparadas à Modernidade aspectos diversos: a família era mais ampla e dispersa, composta de muitos núcleos, dirigida pelo pai (herdeiro do pater familias latino) e submetida à sua autoridade, organizada como uma microempresa, mais como núcleo econômico do que centro de afetos e de investimento social sobre as jovens gerações; a escola era sobretudo religiosa, ligada aos mosteiros e catedrais, não organicamente definida em sua estrutura, nas suas regras e nas sua função, não articulada por "classes de idade" e ligada a uma didática pouco específica e pouco consciente. Com o advento da Modernidade, família e escola sofreram uma profunda renovação (CAMBI, 1999, p. 204)

Tudo isso foi substituído por um modelo racional de organização do ensino. Os alunos foram divididos em salas de aula de acordo com a faixa etária e o nível de estudos. Um currículo foi estabelecido para todos, levando em consideração os diferentes estágios de aprendizagem. Além disso, se estabeleceu um método de ensino, como foi o caso do Ratio studiorum dos padres jesuítas e a Didática Magna de Comênio.

O colégio, embora ainda mantivesse muitas das características da escola medieval, foi se consolidando como um espaço de educação e formação de crianças e jovens. A disciplina passou a ser o elemento fundamental, todos deviam submeter-se a autoridade do professor e a ele responder com respeito e admiração. Como veremos Comênio reforçou a idéia de que não existia ensino sem coação e imposição, embora defendesse que estas deviam ser utilizadas sem o uso da força física, mas de mecanismos psicológicos de persuasão.

O pensamento pedagógico de Comênio foi fruto de uma tentativa de sintetizar o conhecimento científico e racional com a idéia de salvação da alma e de glória a Deus. Em outras palavras "ensinar tudo a todos" foi a forma encontrada pelo pensador morávio para conduzir crianças, jovens e adultos à verdade revelada por Deus: 


\begin{abstract}
A verdade está, de certo modo, dada, seja como germe, em nosso espírito, seja realizada na natureza, seja ainda, e principalmente, revelada na palavra divina impressa nos textos bíblicos. O filósofo não parte da dúvida, mas da certeza implícita na sua opção religiosa cristã. Seu papel é o de um guia para os que estão ainda cegos para essa verdade patente, confundidos na depravação da queda (BARROS, 1971, p.114).
\end{abstract}

$\mathrm{Na}$ abordagem comeniana havia uma constante preocupação com o aprender fazendo, ou seja, era necessário que o aluno tivesse um contato direto com a natureza. Daí a organização de visitas ao campo para que as crianças e jovens pudessem, através dos sentidos aprender de maneira diferente do que constava nos livros apenas:

...tanto quanto possível, a tirarem o conhecimento não dos livros, mas do céu, da terra, dos carvalhos e das faias, isto é, é preciso ensiná-los a conhecer e a investigar as coisas em si mesmas e não por intermédio das observações e testemunhos alheios. Isso significará trilhar o caminho percorrido pelos antigos sábios, haurindo o conhecimento das coisas tão-somente em seu próprio arquétipo. Seja, pois, determinado que: I. Tudo deve ser deduzido dos princípios imutáveis das coisas. II. Nada deve ser ensinado por autoridade pura e simples, mas por demonstrações sensíveis e racionais. III. Nada deve ser ensinado apenas pelo método analítico, mas pelo sintético (COMÊNIO, 2006, pp. 192-193).

Podemos evidenciar no fragmento acima uma clara influência do método experimental de Francis Bacon. Comênio leu a obra do referido filósofo e procurou empregar alguns de seus princípios no seu método de ensino. No entanto existia uma diferença fundamental entre ambos. Bacon estava interessado em comprovar suas teses empiristas, ou seja, chegar à verdade através da experimentação científica. O autor de Didática Magna tinha a intenção de utilizar-se do experimento como método de aprendizagem, uma vez que o conhecimento sensível era mais eficiente que os livros e a memorização sem sentido. Segundo Barros (1971) o pensador da Bohemia acreditava que a verdade estava instalada no interior do ser humano. Ela podia ser revelada, tanto por parte da leitura das Sagradas Escrituras quanto no contato direto com a natureza. Desta constatação decorria uma série de implicações na análise da obra comeniana.

Se a verdade não precisava ser buscada no mundo exterior, como pensava Bacon e outros empiristas, o método didático comeniano era um instrumento de revelação da Verdade Divina. Por isso não podia excluir ninguém, pois todo ser humano possuía dentro de si a capacidade de chegar à verdade e a glória de Deus. Na concepção de Comênio antes do pecado original, o homem era lúcido e pleno conhecedor do Plano Divino, porém com a queda sua mente tornou-se obscura e afastada da verdade. A tarefa principal da educação era resgatar o homem do pecado e o trazer de volta ao plano celeste:

Os exemplos dos autodidatas mostram com muita clareza que o homem, com a orientação da natureza, tudo pode alcançar. Alguns tendo em si mesmos como mestres ou tendo por professores (como diz Bernardo) os carvalhos e as faias (ou seja, passeando pelos bosques e meditando), aprenderam mais que outros através do laborioso ensino dos preceptores. Isso não nos ensina que tudo realmente está no homem? Estão lâmpada, candeeiro, óleo e pavio, e tudo o que é necessário: quem souber produzir 
a centelha, acolhê-la, acender a luz, poderá ver - belíssimo espetáculo os maravilhosos tesouros da divina sabedoria, tanto em si mesmo quanto no macrocosmo (ou seja, que todas as coisas estão dispostas segundo número medida e peso) (COMÊNIO, 2006, p.61).

Uma vez que a verdade pode ser experimentada no convívio com a natureza, o método pedagógico também devia basear-se nas leis naturais para produzir o melhor resultado. Por isso Comênio pensou em um sistema de ensino organizado por diferentes níveis, respeitando assim o estágio de desenvolvimento do indivíduo (escola materna, escola vernácula, escola latina, academia):

Esse método racional e preciso de educação pode ser comparado ao cultivo dos pomares. Isto porque as crianças de seis anos, bem preparadas pelos pais e pela amas, são semelhantes às arvorezinhas plantadas com perícia, que têm raízes bem desenvolvidas e já começam a emitir os primeiros ramos. As crianças de doze anos são semelhantes às árvores que já têm ramos e gemas: o que produzirão ainda não está claro, mas logo estará. Os adolescentes de dezoito anos, que já sabem as línguas e as várias artes, são semelhantes às árvores floridas, que oferecem aprazível espetáculo e odor agradável, prometendo frutos suculentos. Finalmente, os jovens de vinte e quatro anos ou vinte e cinco anos, completamente formados pelos estudos universitários, parecem-se a árvores carregadas de frutos, que já podem ser colhidos de vários modos (COMÊNIO, 2006, p.323).

É interessante observar que o ensino organizado em diferentes níveis, possuía uma semelhança com os estágios de desenvolvimento mental proposto por Jean Piaget ${ }^{1}$ (2010) que inclusive realizou estudos sobre a obra de Comênio. Em 1957 a UNESCO publicou um estudo de Piaget ${ }^{2}$ sobre a atualidade do pensamento do autor tcheco para a educação. No trabalho em questão o pesquisador suíço admitia que mesmo inconscientemente Comênio vislumbrava a existência de uma psicologia do desenvolvimento ao propor a escola organizada em diferentes níveis de ensino.

Apesar das diferenças metodológicas, Comênio pode, sem dúvida, ser considerado um dos precursores da ideia da genética na psicologia do desenvolvimento e o fundador de uma didática progressiva ajustada ao estágio de desenvolvimento que o aluno alcança (Piaget, 2010, p 18).

Nos diferentes graus de organização da escola comeniana o currículo não variava, mas apenas o método de ensinar. Como o conhecimento já estava presente no espírito do aluno, não se acrescentava nada além daquilo que o aluno já possuía de maneira inata. A função das escolas e dos professores era, por meio do método adequado, despertar o saber imanente do indivíduo.

Nessa perspectiva a possibilidade da construção de um indivíduo autônomo é bastante limitada, na medida em que o homem que aprendia caminhava de maneira continua em direção a Deus. O objetivo maior era identificar-se plenamente Criador e criatura como algo único. Aqueles que não aprenderam estavam para sempre perdidos para o pecado e, portanto excluídos eternamente do plano divino. Na realidade Comênio não 
tratou abertamente dessa possibilidade, uma vez que isso seria negar a proposta da sua obra: "ensinar tudo a todos".

O aprender fazendo, defendido pelo autor da Bohemia, não se restringia apenas ao campo de aprendizagem das ciências físicas e naturais, ele avançava também para o campo da moral. Assunto esse que recebeu um capítulo inteiro na Didática Magna. Havia uma verdadeira compulsão em frear os desejos e as vontades. Para isso, segundo o pensamento comeniano, só se podia aprender obedecer obedecendo e a exercer a justiça sendo justo. As principais virtudes eram a prudência, a temperança, a fortaleza (no sentido de resistir às paixões) e a justiça. A razão era a grande responsável para guiar os impulsos humanos, pois somente a sabedoria poderia levar os alunos a julgarem as coisas pelo seu justo valor. Ao contrário de uma educação contemplativa e de recitações que prevaleceu durante o período medieval, Comênio enfatizava a necessidade do educando interiorizar os valores morais e, além disso, exercer uma espécie de autovigilância sobre o seu próprio comportamento:

Que os homens aprendam a temperança para que se habituem a observála sempre, durante todo o período de sua educação, no comer e no beber, no sono e na vigília, no trabalho e na diversão no falar e no calar. Esta regra de ouro deverá ser lembrada aos jovens, "Nunca em excesso": é preciso parar sempre, antes da saciedade e do tédio (COMÊNIO, 2006, pp. 264-265).

O ensino de artes era parte integrante da escola, portanto deveria seguir toda uma metodologia que incluía 11 cânones: seis de uso, três de orientação e dois de exercícios. Em outras palavras aprender fazendo (pintar pintando, esculpir esculpindo, dançar dançando etc.). Deveria se evitar ao máximo os discursos teórico, uma vez que poderia tornar o aprendizado monótono e desinteressante para os aprendizes. No caso específico do ensino de artes o estudo deveria ser feito a partir da reprodução de obras de artes. $\mathrm{O}$ professor deveria corrigir o erro do aluno e instrui-lo para que não errasse mais. Deveria desde o início estabelecer uma forma e uma norma para que a obra de arte fosse imitada. A criação só seria incentivada posteriormente, no começo prevaleceria apenas a cópia e a imitação. Sempre com exemplos fáceis, reais e simples de entender.

Quando o professor fosse introduzir a utilização de um novo instrumento para uso dos alunos deveria demonstrar o seu uso na prática e não por meio de discursos. Os exemplos dados seriam curtos e eficazes, pois o aluno poderia se perder em meio a muitas orientações. Todo o exercício seria iniciado pelos seus rudimentos, jamais pela obra já acabada. Os primeiros exercícios deveriam ser feitos de matéria conhecida. "O sentido é que não se deve sobrecarregar os escolares com coisas que estejam além de sua idade, de sua capacidade de compreensão, de sua condição presente, para não os obrigar a lutar com as sombras (COMÊNIO, 2006, p. 247). O exemplo precisaria ser retirado do cotidiano dos educandos que na concepção do autor tcheco era mais fácil para a criança imitar, uma vez que já o conhecia. Os modelos a serem imitados deveriam ser perfeitos para despertar também reproduções perfeitas.

Por isso é preciso cuidar para que de todas as coisas que devem ser feitas na escola e na vida, sempre haja modelos genuínos, certos, simples e fáceis de imitar, seja eles imagens, pinturas, esquemas de coisas ou ensinamentos e regras brevíssimas, claríssimas, compreensíveis por si mesmas, verdadeiras sem nenhuma exceção (COMÊNIO, 2006, p. 249). 
Toda esta preocupação com os exemplos a serem imitados se explicava pelo cuidado de se construir desde o início uma sólida base de conceitos, procedimentos e conteúdos devidamente dominados e aprendidos. Não se poderia passar para um assunto novo sem que o anterior estivesse suficientemente consolidado. Demorar-se em um determinado assunto, segundo Comênio não era perda de tempo, era um ganho, uma economia que seria compensada futuramente. Estava clara a visão do conhecimento como um edifício em construção. Enquanto as bases não estiveram sólidas não se pode avançar para as etapas seguintes.

Como nas demais disciplinas da escola, os métodos de aprendizagem também deviam acompanhar o desenvolvimento do aluno de acordo com a sua faixa etária. As crianças desde cedo seriam condicionadas a obedecerem aos mais velhos e desta forma fazendo mais a vontade dos outros do que as próprias. Os jovens deviam suportar qualquer tipo de trabalho honesto, uma vez que mantendo as suas mentes e corpos ocupados em atividades contínuas, sérias e agradáveis, estariam distantes dos vícios.

As crianças aprendiam por imitação (de bom ou de ruim), mais uma aproximação com o pensamento piagetiano. Por esse motivo o papel dos pais era importante como exemplo de honestidade e também como guardiões da disciplina familiar. Além dos professores, os pais reforçavam a moral difundida pela escola e moldavam os indivíduos de acordo com as regras. Essas por sua vez seriam buscadas nas palavras dos sábios e da Sagrada Escritura.

Nas palavras do pensador morávio a escola sem disciplina era um moinho sem água. Ela era essencial para fazer com que tudo funcionasse bem e em harmonia. Daí a grande ênfase dada a essa questão. Um ambiente escolar disciplinado colaborava na organização, estimulava a aprendizagem e atraia a atenção dos jovens e crianças. Se isso não ocorresse a culpa era dos professores. Os castigos físicos tão presentes na educação medieval, continuaram existindo, mas eram utilizados somente em último caso. Antes de fazer uso deles, Comênio propunha uma série de procedimentos como advertências, repreensões e até mesmo a coerção psicológica. $\mathrm{O}$ autor sugere se utilizar da repreensão em público, bem como dos elogios, da ironia, das competições como eficientes mecanismos de controle sobre o comportamento dos alunos. A esse respeito dizia: "Mas para isso é essencial que o preceptor esteja presente e que se comporte com seriedade e sem afetação, que repreenda e faça corar quem achar mais negligente, elogiando em público os mais capazes" (COMÊNIO, 2006, p. 313).

$\mathrm{Na}$ verdade Comênio estava propondo abordagens que evitassem o uso da violência e ao mesmo tempo permitisse que o professor utilizasse a ironia e a exposição pública como uma forma mais eficiente de coibir a indisciplina em classe. No entanto como ele mesmo adverte isso deveria ser feito com propriedade por parte do educador para não tornar as punições sem efeito a medida que o mestre apresentar algum sinal de insegurança perante seus alunos.

Também no caso da disciplina escolar, havia uma perceptível preocupação de Comênio em ministrar os castigos e repreensões de maneira moderada e de certo modo tentando convencer o outro que aquilo era para o seu próprio bem. "Educar os jovens para a Igreja e para Deus... para que possam e saibam amar e reverenciar os que educam, não apenas se deixando conduzir aonde convém, mas desejando ardentemente" (COMÊNIO, 2006, p. 315). Indiretamente o autor de Didática Magna estava lançando mão dos mecanismos de condicionamento através do reforço positivo ou negativo que a psicologia experimental iria formular somente no século XIX. Nesse e em outros aspectos podemos identificar a modernidade do pensador da Morávia. Além do que havia um evidente avanço em relação às práticas pedagógicas do período medieval. 
Foi justamente o método de ensino que mais contribuiu para o pensamento comeniano se tornar mundialmente conhecido. A proposta envolvia uma ampliação do acesso à escola para todas as pessoas, de todas as idades e sexos. Esta era a intenção religiosa de salvar a alma da humanidade para Deus, portanto todos teriam a oportunidade de se salvar. Para tal objetivo as pequenas instituições escolares do período medieval não serviam mais, era necessário aumentar a quantidade de alunos para um mesmo mestre. A organização da escola era comparada a uma máquina de imprensa. Havia um fascínio de Comênio por esta atividade que revolucionou a divulgação de informações:

O papel são os alunos, cuja mente é impressa com os caracteres da ciência. Os caracteres tipográficos são os livros escolares e todos os outros instrumentos didáticos, por meio dos quais as matérias que devem ser aprendidas são impressas com facilidade nas mentes. A tinta é a voz do mestre, quando a partir dos livros, ele transmite o sentido das coisas para as mentes dos alunos. A prensa é a disciplina escolar, que predispõe e obriga todos a observar os ensinamentos (COMÊNIO, 2006, p 364).

A comparação entre a escola e o funcionamento de uma máquina revelava uma antecipação daquilo que viria a ser a instituição escolar, principalmente após o advento da revolução industrial e da sociedade dividida em classes sociais. Em outras palavras a gênese da escola de massas com todas as suas características: grande número de alunos; transmissão de conhecimentos científicos, livros didáticos e manuais adaptados para guiar o trabalho do professor; olhar vigilante dos mestres e diretores e castigos e advertências para os que se negarem a cooperar. Era um modelo de organização, cuja maior função era moldar os indivíduos de corpos e mentes dóceis, como Michel Foucault (1994) verificou em seus estudos sobre as instituições burguesas.

O método de aprendizagem comeniano também previa um ensino seqüencial, sem lacunas ou interrupções. Havia uma nítida preocupação com o controle do tempo. O mestre deveria programar muito bem todas as atividades, para que não sobrasse espaço para o ócio. A ociosidade deveria ser combatida de todas as formas:

Realmente, é pela corrupção da natureza que os males medram com maior facilidade e vigor; por isso, é preciso lançar mão de todos os meios para afastar os jovens das ocasiões em que podem ser corrompidos... e o ócio, para que os espíritos não aprendam a agir mal por não terem o que fazer e não se tornem preguiçosos. Por isso, é importante mantê-los sempre ocupados, em coisas sérias ou divertidas, e nunca os deixar ociosos (COMÊNIO, 2006, p. 269).

As repetições, os exames constantes, as competições entre os alunos eram estratégias de aprendizagens descritas na Didática Magna para estimular todos os saberes que já foram impressos por Deus nas mentes dos homens. Eram na realidade exercícios para clarificar o que ficou obscurecido com a queda. Os objetivos da escola vistos sobre esse ângulo, eram multiplicar o número de pessoas instruídas em favor da própria humanidade e da difusão da fé cristã:

E uma vez que nos esforcemos por multiplicar a instrução cristã para infundir, em todas as almas consagradas a Cristo, antes a piedade e depois a cultura e os costumes honestos, podemos esperar aquilo que os oráculos divinos nos ordenam esperar, que um dia a terra se encha do conhecimento do Senhor, assim como o mar está cheio de água (Is XI, 9) (COMÊNIO, 2006, p 370). 


\section{Conclusão}

Entre o antropocentrismo candente do Renascimento e o velho teocentrismo medieval, estava Comênio. Ao propor um método universal de ensino o autor de Didática Magna estava de fato inserido na mentalidade própria de sua época, vislumbrando a sociedade e a escola do capitalismo industrial. A valorização da disciplina, do trabalho honesto, da educação para grandes massas, do aprender fazendo, do controle do tempo, a coerção psicológica ao invés dos castigos físicos, eram indícios de uma nova ordem ou uma ética protestante e do espírito capitalista, tal qual pensou Max Weber (2002) em sua célebre obra. Lutero, Calvino e Comênio possuíam pensamentos convergentes nestes aspectos. Não é por acaso que foram tidos como reformadores.

Retomando aqui a questão inicial que motivou o presente texto podemos dizer que a Didática Magna escrita sob uma perspectiva barroca (tentando conciliar religião e ciência) possui elementos suficientes para justificá-la como uma obra precursora da pedagogia moderna. Ali estavam os elementos que influíram e continuam a exercer uma forte influência sobre os sistemas de ensino. Hoje divididos em diferentes níveis e modelos de organização, a presença de um currículo formal que norteia o trabalho pedagógico ali realizado, as diferentes metodologias de ensino buscam partir da realidade mais próxima do aluno para atingir realidades mais distantes no tempo e no espaço, como o estudo do meio tão utilizado hoje em diversas instituições de ensino, a massificação do ensino nas mais diferentes sociedades pelo mundo afora. Por estas e tantas outras propostas apresentadas por Comênio em sua obra clássica faz dela uma referência singular para toda a pedagogia contemporânea tomada aqui em termos amplos. Não foi por acaso que Piaget (2010) viu no autor tcheco o idealizador de modelo internacional de ensino colaborador e harmônico que educasse essencialmente para paz. Próprio de alguém que vivenciou tantas guerras e perseguições durante toda vida como foi o caso do autor de Didática Magna.

Pensando no Brasil e na nossa realidade educacional. Recentemente universalizamos o acesso ao ensino fundamental, estender para a educação básica ainda não foi possível, assinamos a Declaração de Salamanca ${ }^{3}$, mas não implantamos de fato uma educação inclusiva. Nosso sistema educacional ainda não foi capaz de criar uma escola plenamente democrática, não só no acesso, mas também na qualidade da educação. Nos industrializamos rapidamente, superamos problemas econômicos que pareciam insolúveis, mas temos uma enorme dívida com a educação que vem de séculos e até agora - apesar de várias reformas - não foram equacionados. Por tudo isso e tantos outros problemas podemos verificar que se quer a proposta básica da Didática Magna foi ainda plenamente consolidada entre nós, ou seja, "a arte de ensinar tudo a todos".

\section{Referências}

BARROS, Roque Spencer Maciel de. Ensaios sobre educação. São Paulo: Edusp, Grijaldo, 1971.

CAMBI, Franco. História da Pedagogia. São Paulo: Unesp, 1999.

COMÊNIO, João Amós. Didática magna. 3 ed. São Paulo: Martins Fontes, 2006.

FOUCAULT, Michel. Vigiar e punir. Petrópolis: Vozes, 1994.

GASPARIN, João Luiz. Comênio: a emergência da modernidade na educação. Petrópolis: Vozes, 1997.

HOBSBAWM, Eric. A era das revoluções. Rio de Janeiro: Paz e Terra, 1995. 
KULESZA, Wojciech Andrzej. Comenius: a persistência da utopia em educação. Campinas: Educamp, 1992.

PIAGET, Jean. Jan Amos Comênio. Recife: Fundação Joaquim Nabuco, Massangana, 2010.

WEBER, Max. A ética protestante e o espírito do capitalismo. São Paulo: Martin Claret, 2002.

Notas

\begin{abstract}
${ }^{1}$ Pensador suíço que desenvolveu estudos sobre a psicogênese. Viveu ente 1896 a 1980. Uma de suas obras mais conhecidas foi Introdução à Epistemologia Genética que resume suas teorias do conhecimento. Sua preocupação central era determinar como a criança aprende. Em sua concepção o individuo ao longo de seu desenvolvimento passa por diferentes níveis até atingir o pensamento lógico-abstrato. Desta forma considerava que para cada faixa etária deveria ser proposto a criança desafios diferentes que permitisse a ela avançar e construir novos conhecimentos. Das idéias de Jean Piaget surgiu uma série de correntes pedagógicas genericamente chamadas de construtivistas que buscam aplicar na escola as teorias desenvolvidas pelo pensador.

${ }^{2}$ Neste artigo utilizamos a publicação feita pelo MEC em 2010 que está inserida na "Coleção Educadores".

${ }^{3}$ Documento criado em 1994 na Conferência de Salamanca na Espanha assinado por diversos países, entre eles o Brasil se comprometendo a adotar uma política educação inclusiva para as escolas respeitando as diferenças, apoiando a aprendizagem e respondendo às necessidades especiais de sua clientela.
\end{abstract}

Recebido: $\quad$ março-14 $\quad$ Aprovado: julho-14 